\title{
DO USO DAS NOÇÕES DE CULTURA E CONSUMO PARA REALIZAR REFLEXÕES RELACIONADAS À INTERATIVIDADE PLENA NA TV DIGITAL BRASILEIRA TERRESTRE ${ }^{1}$
}

\author{
ON THE USAGE OF THE NOTIONS OF CULTURE AND CONSUMPTION TO \\ PROPOSE REFLECTIONS RELATED TO FULL INTERACTIVITY IN \\ BRAZILIAN TERRESTRIAL DIGITAL TV
}

\author{
EL USO DE LAS NOCIONES DE CULTURA Y CONSUMO PARA LLEVAR A \\ CABO LAS REFLEXIONES EN RELACIÓN CON LA INTERACTIVIDAD \\ PLENA EN TV DIGITAL TERRESTRE BRASILEÑA
}

\author{
Carlos Eduardo Marquioni \\ $\mathrm{UTP} / \mathrm{PR}$ \\ cemarquioni@uol.com.br
}

\begin{abstract}
Resumo
As ações de interatividade sofisticadas na TV digital terrestre no Brasil são limitadas, no momento em que este artigo é redigido, de fato pela indisponibilidade de um canal de retorno de banda larga para transmissão de dados de retorno e potencialmente por aspectos sociais relacionados à audiência. Abstraindo dificuldades tecnológicas e sociais, o trabalho apresenta os conceitos de cultura e consumo (associados à noção de t-commerce) como fundamentais para analisar a interatividade na TV digital terrestre, caracterizando uma abordagem processual do consumo sob perspectiva cultural que possibilita analogia com as operações de compra realizadas via Web e análise da variação na experiência televisual com o recurso interativo. A abordagem habilita generalização das reflexões em relação a outros modos de interação sofisticados que devem ser disponibilizados futuramente.
\end{abstract}

Palavras-chave: Cultura. Consumo. TV digital. Interatividade.

\begin{abstract}
At the time when this paper is written, sophisticated interactive actions on Brazilian terrestrial digital TV are limited both: in fact due to unavailability of a band width channel to send return data from audience to broadcaster, and potentially due to social issues related to the audience. Abstracting these technological and social difficulties, the work presents the concepts of culture and consumption (associated with the notion of t-commerce) as fundamentals to analyze the interactivity in terrestrial digital television, using a perspective

\footnotetext{
1 Trabalho apresentado oralmente no GP Televisão e Vídeo do XI Encontro dos Grupos de Pesquisa em Comunicação, evento componente do XXXV Congresso Brasileiro de Ciências da Comunicação realizado na UNIFOR - Fortaleza/CE (2012).
} 
that enables the comparison between TV and Web interactions, and to establish a cultural analysis of the variation in television experience related to the interactive resource. The approach makes possible the generalization of reflections considering other sophisticated interactions that can be available in the future.

Keywords: Culture. Consumption. Digital TV. Interactivity.

\section{Resumen}

En el momento cuando se escribe este artículo, las acciones interactivas sofisticadas en TV digital terrestre brasileña son limitadas debido a la falta de un canal de ancho de banda para enviar datos de la audiencia a la emisora y debido a problemas sociales por parte de la audiencia. Abstrayendo estas dificultades tecnológicas y sociales, en este trabajo los conceptos de cultura y consumo (relacionados con la noción de $t$-commerce) se presentan como fundamentales para el análisis de la interactividad en la televisión digital terrestre, a través de una perspectiva de comparación entre las interacciones en la televisión y aquellas en el ambiente de Web, permitiendo una análisis cultural de la variación en la experiencia televisiva con la interactividad. El enfoque hace posible generalizar las reflexiones considerando otras interacciones sofisticadas que se pueden hacer disponibles en futuro.

Palabras clave: Cultura. Consumo. Televisión digital. Interatividad.

\section{INTRODUÇÃO}

A interatividade na televisão "pode ser definida como qualquer coisa que possibilite aos espectadores e produtores de televisão [...] estabelecerem diálogo. Mais especificamente, [...] permite que [os espectadores] façam escolhas e executem ações" (GAWLINSKI, 2003, p. 05). O tipo de interatividade abordado neste trabalho considera que o diálogo entre o público e a emissora ocorre diretamente via TV (sem necessitar de outro meio) e é executado utilizando programas de software (aplicativos) disponibilizados pelas emissoras para realizar as ações.

As interações utilizando a televisão podem apresentar níveis de sofisticação variados. Especialmente devido ao interesse divulgado pelo Governo Federal Brasileiro em proporcionar inclusão digital via TV digital interativa (BARBOSA FILHO; CASTRO, 2008, p. 50), optou-se por abordar neste artigo o formato de interatividade tecnicamente nomeado "interatividade plena" (FERRAZ, 2009, p. 34), em que o televisor adquire características semelhantes às de um computador doméstico conectado à Internet: trata-se do formato mais 
sofisticado de interatividade via TV possível no início da segunda década dos anos $2000^{2}$. Tecnicamente, a interatividade plena tem como premissa a disponibilização de um canal de retorno $^{3}$ de banda larga ${ }^{4}$ associado ao aparelho de TV. Como alternativa de canal de retorno tem sido avaliada a possibilidade de criação de uma rede nacional de telecomunicações de banda larga controlada pelo Governo Federal; contudo, até o momento da elaboração deste trabalho não há um equacionamento definitivo para o tema.

Apesar da semelhança que pode ser observada entre um microcomputador conectado à Internet e um televisor operando em interatividade plena, o trabalho não analisa as interações sofisticadas na televisão considerando o uso do televisor estritamente como um computador: neste segundo caso o espectador acionaria a TV para navegar na Internet ${ }^{5}$. De fato, as reflexões propostas são associadas à experiência de assistir televisão e, mais especificamente, como esta experiência tende a ser afetada quando são disponibilizados recursos na TV que possibilitam a execução de operações que remetem o espectador a situações do ambiente da Web durante o ato de ver televisão (como a realização de compras eletronicamente, por exemplo). Desta forma, ainda que sejam vários os formatos de uso possíveis para a interatividade plena $^{6}$, interessam a este artigo aqueles que impactam

\footnotetext{
${ }^{2} \mathrm{O}$ formato de interatividade plena foi selecionado por se considerar que para que seja caracterizada inclusão digital a audiência necessita domínio de uso do aparato tecnológico não apenas para uso em situações simples (como para participações em enquetes, votando em formato de múltipla escolha), mas também em situações mais sofisticadas.

${ }^{3} \mathrm{O}$ canal de retorno corresponde a um meio de comunicação "integrado ao aparelho de TV do usuário [espectador]" (FERRAZ, 2009, p. 16). Este canal pode ser uma linha telefônica ou uma rede de dados (como a Internet).

${ }^{4} \mathrm{O}$ termo banda é relativo à largura de banda, que corresponde à "quantidade de informação que pode ser transmitida em uma dada quantidade de tempo. [...] [Assim,] quanto mais largura de banda disponível, mais features [características, funcionalidades] podem ser adicionadas a um serviço” (GAWLINSKI, 2003, p. 46). No mundo digital, o termo largura de banda "se refere ao número de bits de informação que pode ser transferido em uma unidade de tempo" (GAWLINSKI, 2003, p. 47). Assim, a banda é relacionada à capacidade de transmissão de dados por unidade de tempo (tipicamente esta capacidade é apresentada em Megabits por segundo - Mbps -, referenciando a transmissão de 1.000 .000 de bits por segundo; cada bit assume os valores 0 ou 1). Bandas estreitas possibilitam a transmissão de pouco volume de dados e, à medida que a banda fica mais larga, aumenta o potencial de transmissão. A telefonia móvel GSM (2G) é um exemplo de banda estreita, enquanto a telefonia móvel 3G utiliza banda larga - o segundo exemplo possibilita transmissão de maior quantidade de dados por unidade de tempo.

5 Trata-se do formato de uso da TV digital interativa nomeado "Internet on television" (GAWLINSKI, 2003, p. 15-16), caracterizado por utilizar o televisor exatamente como se ele fosse um computador.

6 Além do formato "Internet on television" citado anteriormente, existem ainda os "Walled gardens" (GAWLINSKI, 2003, p. 12-14) - referenciados neste artigo como Jardins cercados -, "Enhanced television" (GAWLINSKI, 2003, p. 17-23) - referenciado neste artigo como Televisão expandida -, "Video-on-demand and near-video-on-demand" (GAWLINSKI, 2003, p. 23-24) e "Personal video recorders" (GAWLINSKI, 2003, p. 24-26).
} 
potencialmente a experiência de assistir TV desenvolvida pela audiência em relação à televisão convencional desde os anos de 1950 no Brasil.

O interesse é justificado pelo fato de o público brasileiro se reconhecer na televisão convencional, e ser possível considerar que as competências requeridas para realização de interações sofisticadas devem constituir fatores limitadores para o uso do aparato quando é traçada uma relação entre aspectos de ordem social e a experiência televisual desenvolvida em relação ao meio televisual (particularmente quando é considerado o público alvo da inclusão digital via TV digital terrestre). Há então um risco de as competências requeridas e a dificuldade na execução de interações sofisticadas eventualmente limitarem o potencial de inclusão digital desejado pelo Governo Federal via TV digital terrestre. Mas neste artigo não são abordadas essas restrições ${ }^{7}$ : considera-se aqui que os aspectos sociais relativos à interatividade plena foram equacionados de modo apropriado e que os aspectos de ordem técnica e tecnológica foram tratados. Assim, o público saberia como interagir e haveria televisores digitais (ou conversores para tornar os televisores analógicos aparelhos digitais com possibilidade de interação) disponíveis nos lares brasileiros, além da disponibilização da rede de dados para atuar como canal de retorno de banda larga entre a audiência e as emissoras.

Esse cenário ideal é proposto para que seja possível neste trabalho antecipar reflexões que são fundamentais no momento em que o recurso interativo estiver efetivamente disponível - de modo que haja maior probabilidade de ações de interação sofisticadas (e, por extensão, maior probabilidade de inclusão digital). Para realizar essas reflexões são sugeridas duas noções chave no presente trabalho: cultura e consumo. A materialização dessas noções para os ambientes interativos da TV digital terrestre brasileira via exemplos de aplicação ocorre com o apoio dos conceitos de Jardim cercado e Televisão expandida.

O Jardim cercado corresponde a um formato de uso da interatividade plena que disponibiliza uma

coleção de conteúdos interativos distintos e serviços de uma variedade de companhias [...]. O termo jardim cercado é utilizado porque um limite definido [pelo aplicativo fornecido] restringe o acesso do espectador a conteúdos não regulados [entenda-se que a emissora não queira disponibilizar, durante o ato interativo], diferente do que ocorre na Internet [,

\footnotetext{
7 Alguns destes fatores, como o caráter oral do brasileiro e a necessidade de letramentos (no plural) para realização de ações de interação complexas podem ser consultados em (MARQUIONI, 2011a).
} 
onde é possível navegar para qualquer site a qualquer momento] (GAWLINSKI, 2003, p. 12).

Neste sentido, o Jardim cercado caracteriza um ambiente de software no qual, ainda que o espectador/usuário tenha acesso a recursos da Web, este acesso é limitado (cercado) pelo programa de software que controla o Jardim a um conjunto de operações préestabelecidas.

A Televisão expandida corresponde a um formato de uso que torna

um programa de televisão existente expandido [, aprimorado em relação ao formato de uso quando não é disponibilizado o recurso da interatividade], enquanto o programa é veiculado e durante algum tempo após [sua veiculação]. Os provedores de serviço de televisão expandida tipicamente adicionam overlays [camadas de software que sobrepõem o conteúdo televisual], texto e gráficos aos programas, de modo que os espectadores interajam enquanto assistem TV (GAWLINSKI, 2003, p. 17).

Assim, o conteúdo veiculado sugere a realização de interações indicando ao público que há possibilidade de acesso a conteúdo adicional durante a exibição de um programa de TV (ou de uma peça publicitária). O acesso ao conteúdo em ambos os formatos de uso ocorre via o controle remoto do televisor, e a opção por eles neste artigo é justificada por se considerar que, ao mesclar estas duas alternativas de aplicação da interatividade plena constitui-se um ambiente sofisticado para interação que não apenas proporciona um contexto material para análise da variação na experiência televisual como ultrapassa uma simples navegação convencional na Web. A competência requerida para acesso e manipulação do aplicativo de software que habilita a interatividade a partir do conteúdo televisual poderia assim ser considerada como uma forma de inclusão digital em função tanto do nível de domínio do contexto para uso (o entendimento dos conceitos de Jardim cercado e Televisão expandida) quanto do conhecimento necessário em relação ao aparato tecnológico para a ação.

Sob perspectiva teórica, a noção de cultura que orienta as análises é definida como responsável pelo estabelecimento de "significados comuns [...] [, que] se constituem na vida, são feitos e refeitos" (WILLIAMS, 1989, p. 8). Segundo a definição, a cultura é constituída na duração, caracterizando "uma experiência social que está ainda em processo" (WILLIAMS, 1979, p. 134). Por estar em constituição e influenciar o modo de vida (inclusive atos do cotidiano), é possível utilizar a noção de cultura sugerida para realizar reflexões 
relacionadas ao uso de tecnologias, que influenciam na atribuição de significados pelos atores sociais à medida que eles travam conhecimento com os aparatos tecnológicos (como é o caso da TV digital interativa).

Ainda em relação à perspectiva teórica, para organizar as reflexões optou-se por abordar a realização de compras diretamente via televisão: este formato de consumo é referenciado como t-commerce (television commerce). A opção é justificada pelo fato que $t$ commerce (i) possibilita relação com a realização de compras via Internet - as operações de $e$ commerce (electronic commerce) -, (ii) podendo ser tecnicamente viabilizado segundo o formato de uso de Jardim cercado (uma vez que é possível conceber um portal de compras a ser acessado) associado à Televisão expandida (o caráter de expansão é associado à possibilidade de aquisição de produtos ou serviços apresentados durante a veiculação de conteúdo). Assim, a noção de consumo constitui o segundo conceito chave do artigo: essa noção, quando abordada enquanto processo e sob perspectiva cultural possibilita expandir as análises do potencial de interatividade da TV digital terrestre para outros modos de uso.

$\mathrm{O}$ artigo é dividido em duas seções, além desta Introdução e das Considerações Finais. A seção Consumo: operações além do comércio de bens e serviços analisa o consumo enquanto processo; na perspectiva sugerida, mesmo o leitor deste texto, enquanto leitor, é considerado um consumidor (no caso, do texto propriamente dito). Em t-commerce: a opção pela análise do processo comunicacional via compras diretamente pela televisão é apresentado o conceito de consumo (via TV) e é desenvolvida a justificativa pela opção de operações deste tipo para compor o contexto de análise das reflexões relacionadas à interatividade na TV digital. Finalmente, as Considerações Finais sintetizam as reflexões realizadas e apresentam desdobramentos para o trabalho.

\section{CONSUMO: OPERAÇÕES ALÉM DO COMÉRCIO DE BENS E SERVIÇOS}

Uma quantidade significativa de análises realizadas pela sociedade ocidental (inclusive academicamente) em relação ao consumo tem abordado o tema como um "processo social profundamente elusivo [difícil de explicar] e ambíguo" (BARBOSA; CAMPBELL, 2010, p. 21). O ato de consumir tem sido classificado "como supérfluo, ostentatório ou conspícuo [exagerado]" (BARBOSA; CAMPBELL, 2010, p. 21). A argumentação 
apresentada nessas análises desenvolve a noção que o valor atribuído ao trabalho (que gera o conteúdo a ser consumido) costuma ser vinculado à criatividade, auto-expressão e identidade, enquanto o valor atribuído ao consumo tende a remeter à alienação, falta/perda de identidade, caracterizando-o como um processo individualista e desagregador.

No presente trabalho o consumo é abordado como fato cultural, que atua além da mera mercantilização de bens e serviços, permitindo tratá-lo como "fenômeno central e não [...] simples efeito reflexo da produção" (ROCHA; BARROS, 2008, p. 188). A abordagem possibilita o estabelecimento de elo entre as noções de consumo e cultura (conforme tratada no artigo): via consumo é estabelecido um "conjunto de comportamentos com os quais o sujeito consumidor recolhe e amplia [...] as mudanças culturais da sociedade em seu conjunto" (BACCEGA, 2008, p. 03) na duração - logo, culturalmente. Nesse contexto a comunicação tem um papel chave (BACCEGA, 2010, p. 54), pois ao relacionar comunicação, cultura e consumo é possível tratar três aspectos chave em conjunto: (i) o meio televisual como preparador para o consumo, (ii) os padrões culturais da TV e a (iii) "dimensão política" (ROCHA, 2008, p. 128) do consumo.

Em linhas gerais, o (i) meio televisual pode ser abordado enquanto ambiente de preparação para o consumo em função do fato que os conteúdos veiculados em diversos tipos de programas proporcionam "aprendizado [...] relacionado à discussão de padrões estéticos [...] que servem de discussão e troca de informações" (ROCHA; BARROS, 2008, p. 195). O aprendizado em questão ocorre tanto por identificação do público com o conteúdo veiculado quanto por distanciamento (ROCHA, 2008, p. 127), estranhamento desse público em relação ao conteúdo, quando constatado pela audiência que o conteúdo não é parte de seu repertório. A preparação para o consumo proporcionada pela TV é ainda relacionada ao fato que os conteúdos veiculados realizam uma "reprodução do cotidiano [...] [que] define publicamente produtos e serviços como necessidades, explica-os como modos de uso, confecciona desejos como classificações sociais" (ROCHA; BARROS, 2008, p. 199).

A partir do aprendizado em relação aos padrões sugeridos, estabelece-se um (ii) padrão cultural geral para o público, que influencia na definição da "cultura de um período" (WILLIAMS, 2001, p. 64), pois "[t]udo o que é vivido e feito por uma determinada comunidade em um dado período é [...] essencialmente relacionado, embora, na prática e em detalhes isso nem sempre seja fácil de ser observado" (WILLIAMS, 1971, p. 17). Pode-se 
então dizer que a TV prescreve (SODRÉ, 2010, p. 61) convenções; e estas convenções organizam os significados culturais em um momento determinado, estabelecendo o padrão cultural enquanto "uma resposta seletiva à experiência, um sistema aprendido de sentimento e ação em uma sociedade particular" (WILLIAMS, 2001, p. 98). Mas vale observar que a definição do padrão cultural ocorre em um movimento dialético: enquanto a mídia define padrões, vai também obter no cotidiano as referências que possibilitam essa definição - ou não seria possível reproduzir no conteúdo veiculado as marcas de enunciação do cotidiano que proporcionam a identificação (e reconhecimento ou estranhamento correspondente por parte) da audiência na mídia televisual.

O movimento dialético entre mídia e cotidiano promove finalmente a expansão do desejo de consumo, que pode se referir a uma "mercadoria virtualizada [...] [, um] fluxo do desejo de um 'novo' - acontecimento, informação, objeto" (SODRÉ, 2010, p. 59) estabelecendo relação com a noção da (iii) dimensão política do consumo. Esta dimensão possibilita abordar o ato de consumir como "a posse de uma atitude de natureza quase metanarrativa [...] [que] equivale, assim, a consumir um modo de consumir" (ROCHA, 2008, p. 128). Caracteriza-se então o consumo como "todo um conjunto de processos e fenômenos socioculturais complexos, mutáveis, através dos quais se realizam a apropriação e os diferentes usos de produtos [...] [e] serviços” (ROCHA, 2008, p. 120). Neste sentido, os atores sociais/culturais freqüentemente consomem: não apenas bens ou serviços, mas conhecimento, serviços oficiais, trabalho doméstico - "não se trata mais de 'quem compra o que', mas, [...] quem obtém o que, em que condições de acesso, e que uso se faz das coisas assim adquiridas" (BARBOSA; CAMPBELL, 2010, p. 26).

A opção por utilizar o consumo como referência para análise do processo comunicacional durante as ações de interatividade plena é então justificada pelo fato que a “fluidez, o desenraizamento, a vida líquida, a velocidade no lugar da duração, a aparente predominância da imagem [...] carregam a possibilidade de transmutação de toda a realidade em objetos de consumo" (BACCEGA, 2008, p. 02). Ainda, o "impacto do consumo cotidiano de produtos e serviços define de maneira crucial a nossa existência, interferindo no modo como nos comunicamos e nos afirmamos socialmente" (ROCHA, 2008, p. 128): a sociedade contemporânea consome (para se adequar aos padrões culturais) e é consumida (para fornecer subsídios que habilitam a definição desses padrões culturais - ou a renovação cultural, em 
processo, de padrões) continuamente. E a TV constitui um meio através do qual esta complexa relação é materializada.

\section{T-COMMERCE: A ANÁLISE DO PROCESSO COMUNICACIONAL VIA CONSUMO}

A noção de consumo enquanto processo e associada a características de padrão cultural analisada na seção anterior pode ser aplicada também às operações realizadas no ambiente da Internet. $\mathrm{Na} \mathrm{Web}$, indubitavelmente as operações relacionadas a comércio eletrônico caracterizam a forma mais óbvia de constatação de consumo, ainda que a aplicação da abordagem processual habilite compreender outras operações também como associadas a atos de consumo ${ }^{8}$. A facilidade de constatação da ação de consumo nas compras eletrônicas, associada ao aumento das operações de e-commerce (nome a partir do qual evidentemente deriva o termo $t$-commerce) nos últimos anos motivou a seleção das operações de $t$-commerce para análise neste artigo, por elas constituírem uma espécie de potencial migração do comércio eletrônico para o ambiente da TV.

Merece destaque, contudo, o fato de existirem outras formas sofisticadas de interatividade plena que poderiam ser caracterizadas processualmente como consumo, o que motiva algum aprofundamento na justificativa pela opção de t-commerce. Este tipo de operação foi selecionado, ao invés de outras formas como o t-bank (transposição para o ambiente da televisão do banco via Web) ou o t-government (serviços de governo eletrônico, como consultas a conteúdos de programas sociais) em função também da necessidade de preparação do público da televisão terrestre para realizar operações de interatividade. Ocorre que há risco de uma preparação não satisfatória da audiência para a ação interativa acarretar uma utilização do recurso em escala inferior àquela desejada, planejada ou possível. Neste sentido, é relevante observar a inexistência de recursos relacionados ao uso de banco ou governo eletrônico via televisão no momento da redação deste artigo, enquanto é possível constatar a proliferação de programas e canais de TV dedicados a motivar o consumo (ainda

\footnotetext{
${ }^{8}$ Seguindo a linha da abordagem processual, desde operações triviais como a realização de conversas informais em salas de bate-papo até a realização de práticas religiosas em modo virtual ou o estabelecimento de contatos que propiciam a aproximação familiar utilizando a Rede (MILLER; SLATER, 2001, p. 169) constituem formas de consumir.
} 
que essas compras motivadas via programas ou canais de TV não ocorram diretamente através do televisor).

Complementarmente aos fatos da proliferação do consumo via Web e da existência de programas ou canais dedicados às compras, há ainda um último fator que merece destaque e possibilita afirmar que uma preparação da audiência para consumo em sentido estrito via TV encontra-se em curso. Ocorre que, processualmente, uma ação de interação para comércio eletrônico na Web tem associada a realização de operações bancárias: as transações de compra pela Internet costumam movimentar fluxos de papel moeda sem materialidade. Desta forma, a preparação do público para uso dos serviços bancários em modo eletrônico e a correspondente redefinição da noção de dinheiro (desde a experiência do auto-atendimento até o home banking, passando pelo tele-atendimento bancário) também auxiliaram na preparação para o consumo via Web - e esta preparação para tratar a "abstração do dinheiro como cultura material" (MILLER; SLATER, 2001, p. 167) deve ser útil durante as operações de $t$ commerce.

É importante observar ainda a necessidade da preparação das próprias emissoras para a realização de $t$-commerce: é possível constatar que a realização de uma operação de compra on-line envolve mais ações do que a interação per se, e engloba "estar envolvido sensual e ativamente com um site [...] [que integra] atividades do consumidor [e] que transcendem o contexto comercial específico" (MILLER; SLATER, 2001, p. 165). O processo em questão ultrapassa a compra e venda de bens e serviços: trata-se de um complexo sistema integrado (MILLER; SLATER, 2001, p. 150) que abrange tanto consumidores quanto o próprio fornecedor do produto, além de áreas de negócio da organização responsável pela venda e agentes de suporte relacionados (por exemplo, a empresa responsável pelo envio do produto ao consumidor ou a operadora de cartão de crédito). Essa análise do comércio eletrônico enquanto sistema, de atuação multidisciplinar, evidencia se tratar de mais que simplesmente comprar e estar on-line: de fato, o Website constitui um ambiente integrador de processos entre o público/consumidor e os demais afetados pela operação. Entende-se que contexto equivalente é aplicável às operações de $t$-commerce, e os casos relacionados ao e-commerce caracterizam uma evidente referência, especialmente porque auxiliam a equacionar e tratar de modo apropriado as interfaces (enquanto pontos de contato) entre todos os atores afetados nessa complexa operação sistêmica. A rigor, algumas emissoras já possuem infra-estrutura 
para tratar essas interfaces, no sentido que realizam vendas utilizando o telefone e a Internet mas este artigo não aborda essa preparação por parte das emissoras. Apesar deste breve destaque, conforme vem sendo tratado ao longo das seções do trabalho, o foco aqui não é o aspecto logístico para viabilizar o negócio, mas a necessidade de considerar uma mudança substancial em relação à experiência de consumo quando o espectador utiliza o telefone ou a Web para comprar um produto exibido na TV, comparativamente a quando ele utiliza o próprio televisor para realizar esta operação. Há, neste segundo caso, uma variação que afeta diretamente a maneira de assistir televisão vinculada ao ato de consumir (ou, em termos mais amplos, vinculada a atos de interatividade sofisticados), pois o conteúdo em exibição pode ter (provavelmente exige) atenção deslocada durante a interatividade. A realização de operações de interação pressupõe a exibição de uma interface (em formato tela/página) que deve negociar espaço físico no monitor de TV com o conteúdo televisual transmitido para ser apresentada: o programa de software (a aplicação ${ }^{9}$ ) através da qual é realizada a operação de compra necessita de (ao menos) parte do espaço do monitor de TV que é utilizado desde os primórdios para exibir o conteúdo televisual. Esta negociação de espaço pode ocorrer, tecnicamente, segundo vários formatos (FERRAZ, 2009, p. 35).

Considera-se que mais do que simplesmente interagir, o espectador vai necessitar operar um novo ambiente televisual pois, diferente do que ocorre no ambiente da Web que o usuário acessa com a premissa da interação, na TV digital a premissa (enquanto TV, desde seus primórdios) é assistir ao conteúdo veiculado; a interação seria associada e motivada por uma expansão da TV (Televisão expandida) a partir do conteúdo veiculado. Com a necessidade de negociação da área do monitor para realização de interações é requerida definição da alternativa técnica mais apropriada a utilizar em cada caso para exibir os programas de software, de modo a minimizar o risco de limitar o ato interativo. Concomitantemente ao formato técnico, a limitação pode ter origem no tipo de programa em que o recurso de interatividade plena é disponibilizado, ou a uma associação entre os fatores.

O contexto apresentado sugere que o processo de compra via TV é mais complexo do que a simples migração entre suportes para realização de comércio eletrônico. A rigor, a variação principal não é a substituição do microcomputador conectado à Internet para a televisão digital com canal de retorno utilizando tecnologia de banda larga, mas sim a

\footnotetext{
${ }^{9}$ Forma como costumam ser referenciados os programas de software que viabilizam a interatividade. 
variação na experiência televisual a partir da realização de operações de interatividade plena. E essa variação pode ter origem em fatores tanto sociais quanto tecnológicos. Para exemplificar a afirmação é possível recorrer ao comentário que "[e]xperimentos iniciais com televisão interativa, em meados da década de 1990, foram descartados basicamente como fracassos [...] [, pois q]uase ninguém queria parar de ver televisão para comprar a roupa que um dos amigos de Friends [...] usava" (JENKINS, 2008, p. 93). A citação a Jenkins pode ser analisada sob várias perspectivas ${ }^{10}$. Uma análise sob um viés técnico permite supor que eventualmente a largura de banda disponível no momento citado pelo autor pode ter alguma responsabilidade pela não realização das transações comerciais, em função do tempo requerido para realizar a operação e como este tempo impacta a experiência televisual. Merece destaque o fato que não se trata de mera especulação: Jenkins não cita nominalmente o país a que se refere seu exemplo, mas em função dos programas televisuais analisados ao longo da obra citada do autor, é possível inferir que o fracasso de vendas citado pelo pesquisador é relativo à televisão norte-americana. Ocorre que no mesmo período histórico, no Reino Unido, os serviços de interatividade na televisão reconhecidamente possuíam execução lenta (GAWLINSKI, 2003, p. 49). Ainda que evidentemente se tratem de continentes distintos e que o desenvolvimento da TV digital tenha peculiaridades em cada um desses países, o estado da arte do desenvolvimento tecnológico no momento em questão era compartilhado - inclusive por se tratar de países desenvolvidos. Neste sentido, tecnicamente o fracasso destacado por Jenkins poderia ser justificado em função de uma largura de banda insuficiente, que tornaria a ação de interatividade demorada, desestimulando o consumo.

Vale destacar, ainda sob perspectiva técnica mas sob a lente da usabilidade, que o formato adotado para exibição do aplicativo para compra talvez limitasse a capacidade de assistir televisão. É possível citar como exemplo de limitações relativas à usabilidade o caso do ambiente Open..., desenvolvido pela Sky do Reino Unido e disponibilizado para o público de TV digital em 1999 (alguns anos após o exemplo apresentado por Jenkins). Tratava-se de um ambiente para compras em formato de Jardim cercado que operava tecnicamente em tela cheia $^{11}$. O aplicativo permaneceu no ar apenas durante dois anos e foi substituído por um

\footnotetext{
${ }^{10}$ Análises sob perspectiva da cultura e preparação da audiência para interagir no momento em questão podem ser consultadas em (MARQUIONI, 2011b, p. 140-141).

${ }^{11} \mathrm{Na}$ apresentação do ambiente interativo em tela cheia "a imagem (e o som) da TV desaparece, dando lugar apenas à aplicação" (FERRAZ, 2009, p. 35).
} 
novo ambiente - nomeado SkyActive -, que possibilitava a realização de compras utilizando o recurso de redimensionamento da imagem ${ }^{12}$; esse segundo ambiente - também um Jardim cercado - foi mais utilizado que o primeiro: o formato de exibição da interface para interação exerceu influência direta no uso do recurso.

É necessário considerar ainda a necessidade de coerência para consumo: o espectador provavelmente vai consumir via televisão quando a operação lhe fizer sentido, considerando a relação de ganho e perda associada à interação. Ocorre que no momento em que o espectador opta por realizar uma operação de $t$-commerce, ele também opta por deixar de acompanhar (ou opta por acompanhar com menor atenção) o "fluxo televisual" planejado (WILLIAMS, 2005, p. 89-90). Assim, o uso do recurso de interatividade tende a ser solicitado (no caso de t-commerce, a compra deve efetivamente ocorrer) apenas em relação a uma parcela dos espectadores para a qual a interação seja relevante (ou a aquisição faça sentido), considerando esse ganho e perda em relação ao conteúdo transmitido.

O tipo de programa sendo veiculado é considerado crítico na decisão, e mais que simplesmente oferecer a possibilidade de consumo via TV, há que se avaliar como viabilizar operações de $t$-commerce em cada situação, em relação a cada gênero televisual, considerando a experiência proporcionada por cada tipo de programa, para minimizar o risco de incorrer em simplificações analíticas. Uma vez que o trabalho utiliza a noção de cultura como referência conceitual principal, as "formas culturais" (WILLIAMS, 2005, p. 39-76) da televisão constituem um arcabouço metodológico interessante para orientar a sistematização dos programas televisuais nos quais deve haver tendência do público em interagir.

A situação de ganho e perda comentada pode ser observada também em uma situação de video-on-demand ${ }^{13}$ : ao mesmo tempo em que o espectador opta por assistir a um conteúdo adicional fornecido, ele também opta por deixar de acompanhar o fluxo televisual planejado. Há um ganho em relação a um tema de seu interesse, mas há também uma perda em relação a

\footnotetext{
${ }^{12} \mathrm{Na}$ apresentação do ambiente interativo com redimensionamento da imagem o público pode continuar a assistir TV enquanto interage, pois a tela do televisor é dividida. Neste caso há necessidade de o espectador gerenciar o compartilhamento de sua atenção considerando os dois programas apresentados: o programa de software (o aplicativo através do qual interage) e o programa de TV (o conteúdo televisual propriamente dito).

13 Trata-se de recurso de interatividade plena que possibilita exibição de conteúdo adicional, promovendo reconfiguração (pela audiência) do fluxo televisual planejado.
} 
outro conteúdo - que é veiculado independentemente da opção de interatividade, via o fluxo televisual planejado originalmente pela emissora ${ }^{14}$.

Em ambas as situações, ainda que haja possibilidade técnica de o espectador gravar o conteúdo veiculado enquanto interage (via opções de personal video recorders), a quantidade de alternativas para interação pode promover atribuição de complexidade adicional na experiência televisual - que tradicionalmente é simples, estabelecendo uma "sensação de acesso direto, sem mediação" (WILLIAMS, 2005, p. 135). Esta complexidade adicional no ato de assistir televisão, se não abordada de modo analítico para proporcionar um contexto de uso coerente na práxis, pode eventualmente limitar a tendência interativa.

\section{CONSIDERAÇÕES FINAIS}

Realizar ações de interatividade plena na televisão digital engloba mais do que simplesmente disponibilizar o recurso tecnológico: a complexidade associada requer reflexões analíticas sistematizadas para equacionar o tema, de modo a minimizar os riscos de anacronismos e simplificações demasiadas que eventualmente limitem o uso dos recursos por não considerarem conceitualmente o processo envolvido.

Este trabalho apresentou as noções de cultura e consumo e, mais particularmente, as ações de compras pela TV como sugestão para estabelecimento de um contexto de análise visando tratamento conceitual das operações de interatividade plena. Uma vez que as ações de consumo sejam abordadas enquanto processo, é possível expandir as reflexões realizadas, aplicando-as a outras formas de interação (no caso deste artigo, a relação de ganho e perda com a interatividade foi brevemente abordada nas operações de compra e no caso de videoon-demand).

Para aprofundamento nas reflexões iniciais apresentadas neste trabalho é necessário avaliar os tipos de programa veiculados e sua relação com o consumo. Uma vez que este trabalho considera o próprio ato de assistir televisão no Brasil como caracterizando um fenômeno cultural, e ao constatar que "[t]odo consumo [...] é cultural, envolve significado" uma vez que as opções de consumo são baseadas em “valores, rituais, hábitos [...] de natureza

\footnotetext{
${ }^{14}$ Sobre essa relação de ganho e perda em relação a conteúdos de telejornalismo, recomenda-se a leitura do artigo Televisão digital e diversificação da produção de conteúdos: relato de uma experiência no telejornalismo (FECHINE et al, 2011).
} 
social" (BACCEGA, 2010, p. 58), um desdobramento evidente para este trabalho envolve avaliar como as "formas culturais" (WILLIAMS, 2005, p. 39-76) da televisão apoiariam na sistematização do momento nos quais pode haver tendência do público em interagir. Esta sistematização envolveria identificar o tipo de programa, o formato para interação e o tipo de operação de interatividade plena que teria maior tendência em cada situação. Como fator de complexificação evidente, é necessário abordar neste caso como o formato ao vivo poderia operar em relação à interatividade, especialmente ao observar que este tipo de transmissão é responsável culturalmente por uma espécie de sincronia do cotidiano e por reforçar um sentido de comunhão no Brasil.

Um segundo desdobramento para o trabalho é associado ao fato que a TV tem adquirido um caráter mais individual. Enquanto é possível analisar o televisor como artefato historicamente responsável por proporcionar reunião familiar (no sentido de as pessoas se reunirem para assistir juntas aos programas de TV), o aumento da quantidade desses dispositivos nas residências em certa medida tem provocado um espalhamento dos espectadores entre os cômodos dos domicílios. Ainda, os aparelhos de telefonia celular móvel que recebem o sinal da TV digital devem potencializar esta individualização do ato de ver TV. Neste contexto, há que se avaliar de que forma as redes sociais, que caracterizam lugares para a socialização (MILLER, 2011, p. 85) constituiriam uma nova espécie de sala de estar, definindo uma nova maneira de assistir TV em família: um novo modo de estar com para ver televisão. Ao abordar o consumo enquanto relação e sob perspectiva cultural, é importante considerar os mecanismos de interatividade associados a estas redes sociais como uma alternativa para proporcionar uma "sensação de co-presença" (MILLER, 2011, p. 126) via uma expansão social dos limites domésticos (MILLER, 2011, p. 194). Eventualmente a interatividade pode caracterizar a TV digital como uma alternativa para reaproximação das pessoas, em uma espécie de recuperação do que ocorria inicialmente com a TV analógica, mas em um novo formato de convívio. Na perspectiva deste artigo, em uma nova forma de consumo cultural. 


\section{REFERÊNCIAS}

BACCEGA, Maria Aparecida. Consumo e identidade: leituras e marcas. In: (org.). Comunicação e culturas do consumo. São Paulo: Editora Atlas, 2008. p. 1-11.

BACCEGA, Maria Aparecida. Consumo/educação: relações com o consumo: Importância para a constituição da cidadania. In: Comunicação, Mídia e Consumo - Revista online ESPM, São Paulo, v. 07, no. 19, 2010. Disponível em: <http://revistacmc.espm.br/index.php/revistacmc/article/view/285/198>. Acesso em: 09 set. 2011. p. 49-65.

BARBOSA, Lívia; CAMPBELL, Colin. O estudo do consumo nas ciências sociais contemporâneas. In: __ Cultura Consumo e Identidade. Rio de Janeiro: Editora FGV, [2006] 2010. p. 21-44.

BARBOSA FILHO, André; CASTRO, Cosette. Comunicação digital: Educação, tecnologia e novos comportamentos. São Paulo: Paulinas, 2008.

FECHINE, Yvana et al. Televisão digital e diversificação da produção de conteúdos: relato de uma experiência no telejornalismo. In: Intercom Congresso Brasileiro de Ciências da Comunicação, XXXIV Intercom, 2011, Recife. Anais... Recife: Unicap, 2011.

FERRAZ, Carlos. Análise e perspectivas da interatividade na TV Digital. In: SQUIRRA, Sebastião; FECHINE, Yvana (org.). Televisão Digital: desafios para a comunicação Livro da COMPÓS 2009. Porto Alegre: Editora Sulina, 2009.

GAWLINSKI, Mark. Interactive television production. Oxford: Focal Press, 2003.

JENKINS, Henry. Cultura da Convergência. São Paulo: Aleph, 2008.

MARQUIONI, Carlos Eduardo. A TV digital interativa terrestre e o público brasileiro: Reflexões pela manutenção de uma relação de afeto. In: Intercom Congresso Brasileiro de Ciências da Comunicação, XXXIV Intercom, 2011, Recife. Anais... Recife: Unicap, 2011 a.

MARQUIONI, Carlos Eduardo. Da necessidade de reflexões para além da tecnologia da TV digital interativa no Brasil. Comunicação \& sociedade, Universidade Metodista, v.32, n.55, jan./jun.2011, p. 131-152. 2011 b.

MILlER, Daniel; SLATER, Don. The Internet: An Ethnographic Approach. Oxford: Berg, 2001.

MILLER, Daniel. Tales from Facebook. Cambridge: Polity Press, 2011.

ROCHA, Rose de Melo. Comunicação e consumo: por uma leitura política dos modos de consumir. In: BACCEGA, Maria Aparecida (org.). Comunicação e culturas do consumo. São Paulo: Editora Atlas, 2008. p. 119-131. 
ROCHA, Everardo; BARROS, Carla. Entre mundos distintos: notas sobre comunicação e consumo em um grupo social. In: BACCEGA, Maria Aparecida (org.). Comunicação e culturas do consumo. São Paulo: Editora Atlas, 2008. p. 186-202.

SODRÉ, Muniz. Antropológica do espelho. Petrópolis: Editora Vozes, [2002] 2010.

WILLIAMS, Raymond. Drama from Ibsen to Brecht. Londres: Chatto \& Windus, [1952, 1968] 1971.

WILLIAMS, Raymond. Marxismo e literatura. Rio de Janeiro: Zahar Editores, 1979.

WILLIAMS, Raymond. Television: Technology and Cultural Form. Padstow: Routledge Classics, [1974] 2005.

WILLIAMS, Raymond. Culture is ordinary [1958]. In: Resources of Hope: Culture, Democracy, Socialism. p. 3-18. Londres: Verso, 1989.

WILLIAMS, Raymond. The long revolution. Peterborough: Broadview Press, [1961] 2001.

Original recebido em: $30 / 10 / 2012$

Aceito para publicação em: 03/12/2012

Resumo sobre autor

Carlos Eduardo Marquioni é doutor em Comunicação e Linguagens (UTP/2012), Mestre em Comunicação e Linguagens (UTP/2008) e Bacharel em Análise de Sistemas (PUCCampinas/1994). Docente na UTP/PR e membro do grupo de pesquisa Imagens, sentidos e regimes de interação/CNPQ na mesma instituição. 